\title{
Observation of neutral sulfuric acid-amine containing clusters in laboratory and ambient measurements
}

\author{
J. Zhao ${ }^{1}$, J. N. Smith ${ }^{1,2}$, F. L. Eisele ${ }^{1}$, M. Chen ${ }^{3}$, C. Kuang ${ }^{4}$, and P. H. McMurry ${ }^{3}$ \\ ${ }^{1}$ Atmospheric Chemistry Division, National Center for Atmospheric Research, Boulder, Colorado, 80301, USA \\ ${ }^{2}$ Deptment of Applied Physics, University of Eastern Finland, Kuopio, Finland \\ ${ }^{3}$ University of Minnesota, Department of Mechanical Engineering, Minneapolis, Minnesota, 55455, USA \\ ${ }^{4}$ Department of Atmospheric Science, Brookhaven National Laboratory, Upton, New York 11973, USA
}

Received: 1 July 2011 - Published in Atmos. Chem. Phys. Discuss.: 11 July 2011

Revised: 3 October 2011 - Accepted: 17 October 2011 - Published: 2 November 2011

\begin{abstract}
Recent ab initio calculations showed that amines can enhance atmospheric sulfuric acid-water nucleation more effectively than ammonia, and this prediction has been substantiated in laboratory measurements. Laboratory studies have also shown that amines can effectively displace ammonia in several types of ammonium clusters. However, the roles of amines in cluster formation and growth at a microscopic molecular scale (from molecular sizes up to $2 \mathrm{~nm}$ ) have not yet been well understood. Processes that must be understood include the incorporation of amines into sulfuric acid clusters and the formation of organic salts in freshly nucleated particles, which contributes significantly to particle growth rates. We report the first laboratory and ambient measurements of neutral sulfuric acid-amine clusters using the Cluster CIMS, a recently-developed mass spectrometer designed for measuring neutral clusters formed in the atmosphere during nucleation. An experimental technique, which we refer to as Semi-Ambient Signal Amplification (SASA), was employed. Sulfuric acid was added to ambient air, and the concentrations and composition of clusters in this mixture were analyzed by the Cluster CIMS. This experimental approach led to significantly higher cluster concentrations than are normally found in ambient air, thereby increasing signalto-noise levels and allowing us to study reactions between gas phase species in ambient air and sulfuric acid containing clusters. Mass peaks corresponding to clusters containing four $\mathrm{H}_{2} \mathrm{SO}_{4}$ molecules and one amine molecule were clearly observed, with the most abundant sulfuric acid-amine clusters being those containing a $\mathrm{C} 2$ - or $\mathrm{C} 4$-amine (i.e. amines with masses of 45 and $73 \mathrm{amu}$ ). Evidence for C3- and C5amines (i.e. amines with masses of 59 and $87 \mathrm{amu}$ ) was also
\end{abstract}

Correspondence to: J. Zhao

(jzhao@ucar.edu) found, but their correlation with sulfuric acid tetramer was not as strong as was observed for the $\mathrm{C} 2$ - and $\mathrm{C} 4$-amines. The formation mechanisms for those sulfuric acid-amine clusters were investigated by varying the residence time in the inlet. It was concluded that the amines react directly with neutral clusters and that ion-induced clustering of sulfuric acid cluster ions with amines was not a dominant process. Results from ambient measurements using the Cluster CIMS without addition of sulfuric acid have shown that the sulfuric acid-amine clusters were reasonably well correlated with sulfuric acid tetramer and consistent with the SASA experiments at the same Boulder sampling site. Also, clusters that contain $\mathrm{C} 2$ - or $\mathrm{C} 4$-amines were more abundant and better correlated with sulfuric acid tetramer than other types of amine containing clusters. However, ambient measurements of sulfuric acid-amine clusters remain difficult and highly uncertain because their concentrations are only slightly above background levels, even during nucleation events.

\section{Introduction}

New particle formation is frequently observed in the tropospheric boundary layer (Kulmala et al., 2004). Field observations (e.g. Lihavainen et al., 2003; Kerminen et al., 2005; Laaksonen et al., 2005) and modeling studies (Ghan et al., 2001; Spracklen et al., 2008; Kuang et al., 2009; Merikanto et al., 2009) have shown that particles produced by nucleation contribute significantly to the total concentrations of Cloud Condensation Nuclei (CCN) on the global scale and hence have important climate implications. However, the formation mechanisms for freshly-formed nuclei at a microscopic molecular scale are not yet well understood. Field observations have shown a negligible contribution of ion clusters to new particle formation and growth in the boundary

Published by Copernicus Publications on behalf of the European Geosciences Union. 
layer during the summertime, when temperatures are high (Eisele et al., 2006; Iida et al., 2006; Manninen et al., 2010). Hence neutral nucleation processes must be dominant for summertime events in the boundary layer, although ioninduced/mediated nucleation can be important, especially in the upper atmosphere or in the boundary layer under cold conditions (Turco et al., 1998; Yu and Turco, 2000, 2001; Yu et al., 2008).

Field observations have shown that atmospheric nucleation involves sulfuric acid as the principal nucleating precursor (Weber at al., 1996, 2001). Recently, a power law relationship between the production rate of $1 \mathrm{~nm}$ nuclei, $J_{1}$ (the rate of stable clusters formed, $\mathrm{cm}^{-3} \mathrm{~s}^{-1}$ ), and the concentration of sulfuric acid (molecule $\mathrm{cm}^{-3}$ ) of the form $J_{1}=K\left[\mathrm{H}_{2} \mathrm{SO}_{4}\right]^{P}$ has been employed to explain atmospheric observations of new particle formation, where $K, P$ are the empirically-determined, campaign-constrained parameters. Existing field studies (Sihto et al., 2006; Riipinen et al., 2007; Kuang et al., 2008) have found that $1 \leq P \leq 2$. The two extremes of the exponent, 1 and 2, correspond to the activation (Kulmala et al., 2000, 2006) and kinetic (McMurry and Friedlander, 1979; McMurry, 1980, 1983) models for new particle formation, respectively. The activation model assumes that nucleation occurs through the activation of thermodynamically stable clusters containing only one $\mathrm{H}_{2} \mathrm{SO}_{4}$ molecule, while the kinetic model assumes that critical clusters formed by nucleation contain two $\mathrm{H}_{2} \mathrm{SO}_{4}$ molecules. Kuang et al. (2008) and Riipinen et al. (2007) have shown that for the kinetic model (i.e. for $P=2$ ), the pre-factor $K$ can vary by several orders of magnitude among different measurement locations for a given sulfuric acid concentration. This large variability in $K$ from one location to another (e.g. from an urban city to a forested area) implies that atmospheric nucleation must be a multi-component process that involves additional species besides sulfuric acid and water (bound with $\mathrm{H}_{2} \mathrm{SO}_{4}$ by intermolecular interactions such as hydrogen bonding). There is a need to understand factors that affect $K$, so that nucleation can be accurately described in atmospheric models (Kuang et al., 2010).

Laboratory flow-tube measurements have shown large discrepancies in the number of sulfuric acid molecules in the critical clusters, ranging widely from one to twenty-one (Ball et al., 1999; Zhang et al., 2004; Berndt et al., 2005, 2006; Kulmala et al., 2007; Young et al., 2008; Benson et al., 2008, 2009, 2010; Sipila et al., 2010). Early laboratory studies (e.g. Ball et al., 1999; Zhang et al., 2004) estimated the number of sulfuric acid molecules in the critical clusters to be $8-10$. Recent measurements, however, have shown that this number is smaller, e.g. 4-6 (Benson et al., 2010) or even as small as $1-2$, consistent with atmospheric observations (Sipila et al., 2010). In the latter case, the authors contrasted their measurements with other previous experiments by employing an improved particle counter capable of detecting particles as small as $1.2 \mathrm{~nm}$. The primary reason for these discrepancies is that during typical residence times in the flow reactors used for most of these experiments (typically 1-2 min), nucleated particles cannot grow to sizes that can be detected. For example, growth rates under typical ambient conditions range from $1-10 \mathrm{~nm} \mathrm{~h}^{-1}\left(\sim 2 \times 10^{-2}-2 \times 10^{-1} \mathrm{~nm} \mathrm{~min}^{-1}\right)$, so particles might not even grow to $1 \mathrm{~nm}$ unless concentrations of condensing vapors significantly exceed ambient levels. In addition, in most previous experiments, the nucleation rates $(J)$ were actually either assumed equal to the formation rates of particles larger than $3 \mathrm{~nm}\left(J_{3}\right)$ or extrapolated from $J_{3}$ by assuming a constant growth rate from 1 to $3 \mathrm{~nm}$ (Weber et al., 1997; Kerminen and Kulmala, 2002; Lehtinen et al., 2007). However, if the growth rates are size-dependent, this extrapolation would be invalid. Under such conditions, it would not be possible to infer accurate values of nucleation rates from measurements made using commercial condensation particle counters. Because particles grow to sizes that can readily be detected by existing instrumentation in the atmosphere, reported values of $P$ should be valid with the caveats on uncertainty that have been discussed in the literature. In addition to limitations of condensation particle counters, laboratory studies are also plagued by the presence of impure gases that affect observed nucleation rates yet are present at concentrations too low to be measured by existing instruments. Compounds that are likely candidates include ammonia, amines, and other organic compounds (Kurtén et al., 2008; Zhang et al., 2009; Zhao et al., 2009; Berndt et al., 2010; Metzger et al., 2010; Wang et al., 2010a; Nadykto et al., 2011). Recent measurements from the CLOUD chamber experiment highlighted the importance of ammonia in atmospheric nucleation and found that a mixing ratio of $100 \mathrm{ppt}$ ammonia can increase the nucleation rate of sulfuric acid particles more than 100-1000 fold (Kirkby et al., 2011). It is therefore necessary to identify those compounds and to quantify their effects on nucleation rates.

To overcome these limitations of laboratory studies and to allow more fundamental studies of nucleation mechanisms pertinent to the atmosphere, we have focused on developing methods to measure the composition and concentrations of ambient neutral molecular clusters and nanoparticles formed by nucleation in the atmosphere. Recently, two new instruments have been developed: the cluster chemical ionization mass spectrometer (the Cluster CIMS) (Zhao et al., 2010) and the scanning mobility spectrometer equipped with a diethylene glycol-based condensation particle counter (DEG SMPS) (Jiang et al., 2011a). The Cluster CIMS is an outgrowth of the Selected Ion Chemical Ionization Mass Spectrometer (SICIMS) developed by Eisele and co-workers (Eisele et al., 1993). It measures sulfuric acid monomers as well as neutral molecular clusters containing up to five sulfuric acid molecules, with a sensitivity that allows for measurements of these clusters during atmospheric nucleation events. Direct measurements of neutral molecular clusters provide important insights into the nucleation process because it is now recognized that neutral molecular clusters bound by intermolecular interactions are responsible for the initial stage 
of this dynamic nucleation process in the boundary layer. The DEG SMPS was recently developed based on the work by McMurry and co-workers (Iida, 2008; Iida et al., 2009; Jiang et al., 2011a). It provides reliable measurements of nano condensation nuclei (nano $\mathrm{CN}$ ) down to about $1 \mathrm{~nm}$ in diameter and enables one to revisit the relationship between the nearly directly-measured nucleation rates (which, from our Cluster CIMS and DEG SMPS measurements, can be approximately represented as the formation rate of $1 \mathrm{~nm}$ particles, $J_{1}$ ) and concentrations of the precursors (e.g. sulfuric acid) so that the pre-factor $K$ can be better constrained. Measurements employing the two new instruments during a recent field campaign, the Nucleation and Cloud Condensation Nuclei (NCCN), carried out in Atlanta, Georgia during summer 2009, provided the first complete size spectrum of atmospheric new particle formation from individual molecules, to molecular clusters, to submicrometer particles (Jiang et al., 2011b). One important finding from this field campaign is that the critical cluster contains fewer than three sulfuric acid molecules (Jiang et al., 2011b). This follows from our ambient Cluster CIMS observations that the concentrations of sulfuric acid trimer clusters are typically 3 orders of magnitude below the concentrations of sulfuric acid monomer, but that concentrations of clusters larger than the trimer decrease gradually and monotonically with increasing size, suggesting the absence of a nucleation barrier beyond the trimer.

Searching for nucleating molecular clusters has been an important focus in atmospheric nucleation research. Clusters containing up to eight $\mathrm{H}_{2} \mathrm{SO}_{4}$ molecules and those containing both $\mathrm{H}_{2} \mathrm{SO}_{4}$ (up to six molecules) and $\mathrm{NH}_{3}$ (up to five molecules) have been measured under laboratory experimental conditions (Eisele and Hanson, 2000; Hanson and Eisele, 2002). Sulfuric acid clusters $\left(\mathrm{H}_{2} \mathrm{SO}_{4}\right)_{n}(n=2-$ 8 ) were produced inside a cooled flow tube at $T=230$ $260 \mathrm{~K}$ and $\mathrm{RH}=20-65 \%$ by introducing elevated sulfuric acid concentration $\left(1-3 \times 10^{9} \mathrm{~cm}^{-3}\right)$ (Eisele and Hanson, 2000). Clusters containing both sulfuric acid and ammonia $\left(\mathrm{H}_{2} \mathrm{SO}_{4}\right)_{n} \cdot\left(\mathrm{NH}_{3}\right)_{m}(2 \leq n \leq 6,0 \leq m \leq n-1)$ were generated by introducing both sulfuric acid and ammonia to a warmer flow tube $(\sim 285 \mathrm{~K})$ (Hanson and Eisele, 2002$)$. The clusters were then detected with the SICIMS, and concentrations of neutral clusters as high as a few times $10^{6} \mathrm{~cm}^{-3}$ were estimated. The SICIMS measured clusters containing both $\mathrm{H}_{2} \mathrm{SO}_{4}$ and ammonia, showing the possibility for measuring neutral clusters containing both $\mathrm{H}_{2} \mathrm{SO}_{4}$ and basic molecules (e.g. amines) with the Cluster CIMS, which operates on principles similar to the SICIMS.

This paper explores effects of amines on cluster composition in ambient air. Amines are basic organic compounds that are abundant in the atmosphere and might react with acidic clusters (Ge et al., 2010a, b). About 150 gaseous amines have been identified in the atmosphere from various sources including animal husbandry, waste incinerators, automobiles and oceans (Cadle and Mulawa, 1980; Schade and Crutzen, 1995; Facchini et al., 2008). Their concentrations can be as high as $23 \%$ of the ammonia concentrations (Sorooshian et al., 2008). Recent measurements during NCCN in Atlanta, GA showed that gas phase concentrations of certain amine compounds approached levels of several tens of ppt (Jiang et al., 2011b; Hanson et al., 2011). Most of the atmospheric amines are strong bases and soluble in water, hence sinks of amines may include physical removal by dry and wet deposition and chemical removal by reactions with acids and atmospheric oxidants (e.g. $\mathrm{OH}$ radicals, $\mathrm{O}_{3}$, and $\mathrm{NO}_{3}$ radicals) (Murphy et al., 2007; Malloy et al., 2009). Many atmospheric gaseous amines (e.g. aliphatic amines) may undergo acid-base reactions with inorganic acids (e.g. $\mathrm{H}_{2} \mathrm{SO}_{4}, \mathrm{HCl}$ and $\mathrm{HNO}_{3}$ ) or organic acids (e.g. carboxylic acids) to form inorganic or organic salts. These salts have low vapor pressures that would allow them to contribute significantly to formation and growth of secondary organic aerosols. Thermodynamic models (Barsanti et al., 2009) have shown that aminium salts, formed from atmospherically relevant organic acids and amines, can contribute considerably to growth of freshly nucleated particles. These aminium salts have been observed in atmospheric nanoparticles (about $10 \mathrm{~nm}$ in size) during new particle formation events in recent field measurements (Smith et al., 2010). Recent quantum chemical calculations also showed that amines likely enhance sulfuric acid-water nucleation more efficiently than ammonia in the atmosphere due to the facts that sulfuric acid-amine complexes/clusters are bound more strongly and are more stable than their ammonia counterparts (Kurtén et al., 2008), suggesting that amines may produce clusters that overcome the nucleation barrier. Experimental studies by Bzdek et al. (2010a, b) showed that amines can efficiently displace ammonia from ammonium salts, thereby contributing to the formation of stable clusters and their subsequent growth. Other laboratory measurements also demonstrated the important roles of amines in sulfuric acid-water nucleation involving trimethylamine (Erupe et al., 2011), dimethylamine (Wang et al., 2010b) and tert-butylamine (Berndt et al., 2010). These measurements focused on enhancement factors of particle formation involving amines compared to binary sulfuric acid-water nucleation. Clearly the involvement of amines in cluster formation and growth needs to be further explored at the molecular level in order to understand their roles in atmospheric nanoparticle production.

In this study, semi-ambient signal amplification experiments were performed by addition of laboratory generated sulfuric acid with a concentration of $(1-5) \times 10^{8} \mathrm{~cm}^{-3}$ to ambient air entering the inlet of the Cluster CIMS. It should be noted that sulfuric acid concentrations above $1 \times 10^{8} \mathrm{~cm}^{-3}$ have been observed previously in urban ambient air at locations such as Atlanta and Mexico City, thus this technique would provide valuable information (e.g. mass identification) for ambient measurements. Peaks corresponding to masses of clusters containing four $\mathrm{H}_{2} \mathrm{SO}_{4}$ molecules and one amine molecule were clearly observed after sulfuric acid addition. The intensities of these sulfuric acid-amine 
clusters and sulfuric acid tetramer were well correlated. The results from these laboratory studies helped to refine the measurement technique so that it can then be applied directly to ambient measurements. Furthermore, the first measurements of sulfuric acid-amine clusters from ambient air during nucleation events are reported. Correlations between concentrations of sulfuric acid-amine clusters and sulfuric acid tetramer, and 1-2 nm particles were explored. Mechanisms for the formation of neutral sulfuric acid-amine clusters in the atmosphere are proposed.

\section{Experimental}

\subsection{Semi-Ambient Signal Amplification (SASA) measurements}

As shown in Fig. 1, sulfuric acid vapor was added through a Pyrex side arm flow tube $(2.2 \mathrm{~cm}$ ID and about $120 \mathrm{~cm}$ in length) to ambient air sampled through the Cluster CIMS inlet at about $90 \mathrm{lpm}$. In the presence of oxygen and water, sulfuric acid was generated by the reaction of $\mathrm{SO}_{2}$ with $\mathrm{OH}$ produced by photodissociation of water vapor by a UV lamp $(\lambda=185 \mathrm{~nm})$ (Seinfeld and Pandis, 1998). Clusters containing $\mathrm{H}_{2} \mathrm{SO}_{4}$ were formed in the side arm reactor and along the inlet where a residence time that was varied from 3 to $9 \mathrm{~s}$ allows further reactions of these clusters with ambient trace gases before the resultant clusters were chemically ionized and detected by the Cluster CIMS (with a mass resolution of $1 \mathrm{amu}$ ). The side arm flow tube was extended $1-2 \mathrm{~cm}$ radially into the inlet to minimize wall loss of sulfuric acid. The $\mathrm{SO}_{2} / \mathrm{O}_{2}$ flow was introduced into the flow tube by a movable injector that bypassed direct exposure to the lamp to avoid photochemical decomposition of $\mathrm{SO}_{2}$ and $\mathrm{O}_{2}$. Water vapor was carried into the side arm reactor by passing a portion (about $1 \mathrm{lpm}$ ) of $10 \mathrm{lpm}$ pure $\mathrm{N}_{2}$ flow through a water reservoir (deionized water, resistivity $=18.4 \mathrm{M} \Omega \mathrm{cm}$ ). The humid $\mathrm{N}_{2}$ flow was then introduced into the reactor, upstream of the locations where reagent ions were added and the Cluster CIMS samples were extracted. The $10 \mathrm{~cm}$ ID stainless steel inlet was similar to that used for ambient measurements except it was made longer to allow for longer residence times. The inlet flow was maintained in the laminar regime (Reynolds number $=1500)$ using restricted tubing and a diaphragm pump. Concentrations of sulfuric acid were measured downstream of the inlet by the Cluster CIMS, as discussed below.

A detailed description of the Cluster CIMS along with illustrative measurements from Atlanta, GA, can be found in recent publications (Zhao et al., 2010; Jiang et al., 2011b). Only the aspects relevant to the present study are described in this work. The reagent ions $\mathrm{NO}_{3}^{-} \cdot\left(\mathrm{HNO}_{3}\right)_{n}(n=1,2)$ were generated by introducing trace amounts of $\mathrm{HNO}_{3}$ from a temperature regulated vial into a flow of about $2 \mathrm{lpm}$ pure $\mathrm{N}_{2}$. The combined flow then passed through an ${ }^{241} \mathrm{Am}$ ion source

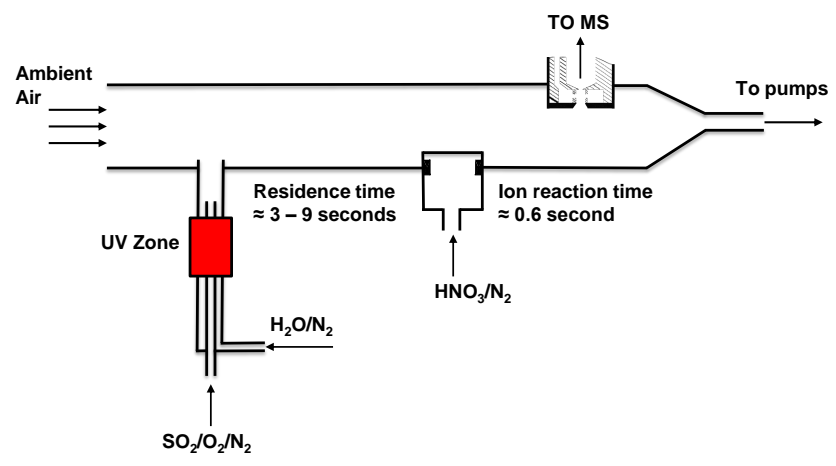

Fig. 1. Experimental setup for the Semi-Ambient Signal Amplification (SASA) measurements. Sulfuric acid was generated in-situ by reactions of $\mathrm{SO}_{2}$ with $\mathrm{OH}$ radicals that were produced by photolysis of water vapor in the side-arm reactor. The sulfuric acid-amine clusters were formed in the inlet, subsequently detected with the Cluster CIMS. The residence time in the inlet varied between 3 and $9 \mathrm{~s}$.

(radioactivity $=27.8 \mathrm{MBq}$ ). Clusters and other trace gases that are more acidic than the neutral form of the reagent ions can exchange a proton with the reagent ions. The resulting ions/cluster ions are then guided into the Cluster CIMS by an electric field applied to the tube. A very small fraction of flow (around $200 \mathrm{sccm}$ ) is extracted through a $150 \mu \mathrm{m}$ diameter aperture into the vacuum chamber. A dry, pure $\mathrm{N}_{2}$ buffer gas $(\sim 400 \mathrm{sccm})$ is injected just before the ions reach the aperture to evaporate the water molecules from the cluster ions to simplify the spectra. This $\mathrm{N}_{2}$ flow minimizes the amount of water vapor entering the vacuum system and reduces the likelihood that water will cluster with the core ions (e.g. $\left.\mathrm{HSO}_{4}^{-} \cdot\left(\mathrm{H}_{2} \mathrm{SO}_{4}\right)_{n}(n=0-3)\right)$ in the cold supersonic jet expansion. It can also prevent ambient fine particles from entering the vacuum system and blocking the aperture. The sampled ions are then guided by a conical octopole, where they are focused and transported efficiently into the quadrupole mass analyzer and subsequently detected by an electron multiplier. The Cluster CIMS has been calibrated using an electrospray coupled to a high resolution differential mobility analyzer (ES-HDMA) (Zhao et al., 2010) and the resultant calibration factors are used when calculating the concentrations of the measured compounds/clusters.

The SASA experiments were performed during the winter and spring, when ambient sulfuric acid concentrations were low $\left(10^{6}-10^{7} \mathrm{~cm}^{-3}\right)$ and hence concentrations of the nucleating/nucleated clusters are typically close to or below the detection limit of the Cluster CIMS even during nucleation events (Zhao et al., 2010). Although there are no direct measurements of ambient amines in Boulder, $\mathrm{CO}$, where these measurements were carried out, based on measurements at other locations we believe amine concentrations were likely comparable to or higher than those of sulfuric acid during nucleation events (Jiang et al., 2011b; Hanson et al., 2011). 
By adding elevated concentrations of sulfuric acid, more sulfuric acid and its clusters are available for reactions with ambient trace gases such as amines. This is a way of amplifying the sulfuric acid related cluster signals in the Cluster CIMS spectra while leaving the rest of the mass spectrum largely unaffected so that the concentrations of the resultant clusters are more easily distinguished from other background compounds. This signal amplification technique is particularly useful when ambient sulfuric acid concentrations are low. One advantage of experiments performed during the cold winter seasons is that low temperature may facilitate the formation and growth of sulfuric acid clusters (Eisele and Hanson, 2000; Hanson and Eisele, 2002). However, cool temperatures might also lead to lower concentrations of amines produced by photo-chemical oxidation or biogenic activity. Also, if local sources such as agricultural operations are significant sources of amines, concentrations might also be greatly affected by wind direction. Our experiments were performed both in winter and in spring, when temperature and photochemical activity were likely quite different. The Cluster CIMS performed measurements alternatively on single ion scan mode with masses including the reagent ions, sulfuric acid monomer, dimer, trimer and tetramer ions, and on spectral scan mode from $\mathrm{m} / \mathrm{z} 200$ to 500 . The Cluster CIMS was primarily operated with relatively long ion reaction times (an ion reaction time of $0.6 \mathrm{~s}$ was used in this case) and occasionally with varying ion reaction times.

Our previous measurements of neutral molecular clusters focused on the core ions in the form $\mathrm{HSO}_{4}^{-} \cdot\left(\mathrm{H}_{2} \mathrm{SO}_{4}\right)_{n-1}$ $(n \leq 5)$ that exclude water and other stabilizing components (e.g. ammonia or amines) based on the hypothesis that those components would fall apart upon ionization or evaporate in the vacuum (Zhao et al., 2010). For example, the high bonding energy (about $42 \mathrm{kcal} \mathrm{mol}^{-1}$ ) between $\mathrm{HSO}_{4}^{-}$and $\mathrm{H}_{2} \mathrm{SO}_{4}$ in sulfuric acid dimer ion $\left(\mathrm{HSO}_{4}^{-} \cdot \mathrm{H}_{2} \mathrm{SO}_{4}\right)$ exclusively prevents clustering of this ion $\left(\mathrm{HSO}_{4}^{-}\right)$with other compounds (Lovejoy and Curtius, 2001). However, previous experiments with ammonia have shown that deprotonated clusters containing 4 or more sulfuric acid molecules are expected to be stable enough to survive through chemical ionization and mass spectral analysis (Eisele and Hanson, 2000; Hanson and Eisele, 2002). Therefore, because the sensitivity of the cluster CIMS decreases substantially for clusters larger than tetramers (Zhao et al., 2010) and because clusters smaller than tetramers are likely to lose stabilizing compounds (e.g. ammonia and amines), this study focuses on tetramers.

\subsection{Ambient measurements}

An intensive measurement period of atmospheric new particle formation and growth was carried out at the Foothills Laboratory of the National Center for Atmospheric Research (NCAR) in Boulder, Colorado in the summer of 2010. Detailed descriptions of the geographic and meteorological conditions of Boulder that are pertinent to this study can be found in Zhao et al. (2010). The campaign was aimed at measurements of the complete size spectrum of new particle formation from molecules, nucleating molecular clusters, nanoparticles as small as $1 \mathrm{~nm}$, and particles up to $0.5 \mu \mathrm{m}$. Parallel measurements of nanoparticles down to $1 \mathrm{~nm}$ were made by two DEG systems (one from Brookhaven National Laboratory and the other from University of Minnesota) (Iida et al., 2009; Jiang et al., 2011a). The particle size distribution (PSD) system measured particles in a size range of 10 $500 \mathrm{~nm}$ (McMurry et al., 2000; Woo et al., 2001; Iida, 2008; Iida et al., 2008). In order to improve the sensitivity in ambient measurements, the Cluster CIMS only measured selected ions such as deprotonated sulfuric acid clusters, clusters containing both sulfuric acid and various amines, with a typical cycle time of $5 \mathrm{~min}$. The clusters containing both sulfuric acid and amines were assigned according to their masses and the time-dependent behavior of other photochemical products.

\section{Results and discussion}

\subsection{Measurements of sulfuric acid-amine clusters in the SASA experiments}

Sulfuric acid concentrations measured at the end of the inlet were in the range $1-5 \times 10^{8} \mathrm{~cm}^{-3}$ and loss of sulfuric acid on the wall, mainly by diffusion, was minor (less than $10 \%$ ). The residence times used, about 3 and $9 \mathrm{~s}$, were sufficient to allow the formation of sulfuric acid clusters and their reactions with ambient trace gases and sulfuric acid vapor. Figure 2 shows mass spectra in the range of 300-500 amu before and after sulfuric acid was added to the Cluster CIMS inlet. Before sulfuric acid addition, a group of peaks with a mass interval of 14-16amu was clearly seen in the spectrum. We hypothesize that they are high molecular weight organic compounds, as discussed in our previous paper (Zhao et al., 2010). After addition of about $3 \times 10^{8} \mathrm{~cm}^{-3}$ sulfuric acid, some new peaks distinctly emerged. These peaks include $\mathrm{m} / \mathrm{z} 354,371,391,408,425$, 436, 450, and $464 \mathrm{amu}$. The $m / z, 354$ and 371 were assigned to be sulfur related compounds, possibly produced from the $\mathrm{SO}_{2}$ oxidation, followed by reactions with nitrate ions. Their possible molecular formulae are $\mathrm{NO}_{3}^{-} \cdot \mathrm{SO}_{4} \cdot\left(\mathrm{H}_{2} \mathrm{SO}_{4}\right)_{2}$ and $\mathrm{NO}_{3}^{-} \cdot \mathrm{SO}_{4} \cdot\left(\mathrm{H}_{2} \mathrm{SO}_{4}\right)_{2} \cdot \mathrm{NH}_{3}$, respectively. Compounds corresponding to $\mathrm{m} / \mathrm{z} 408$ and 425 are thought to be sulfuric acid tetramer clusters that contain one and two $\mathrm{NH}_{3}$, respectively. These ammonia clusters were observed in previous laboratory measurements (Eisele and Hanson, 2000; Hanson and Eisele, 2002). Peaks corresponding to clusters containing three $\mathrm{H}_{2} \mathrm{SO}_{4}$ and one or two $\mathrm{NH}_{3}$ were not clearly seen in the spectra, consistent with the previous observations (Eisele and Hanson, 2000; Hanson and Eisele, 2002) that these clusters are not stable enough to survive the ionization and analysis conditions. The $m / z 391$ is deprotonated sulfuric acid 


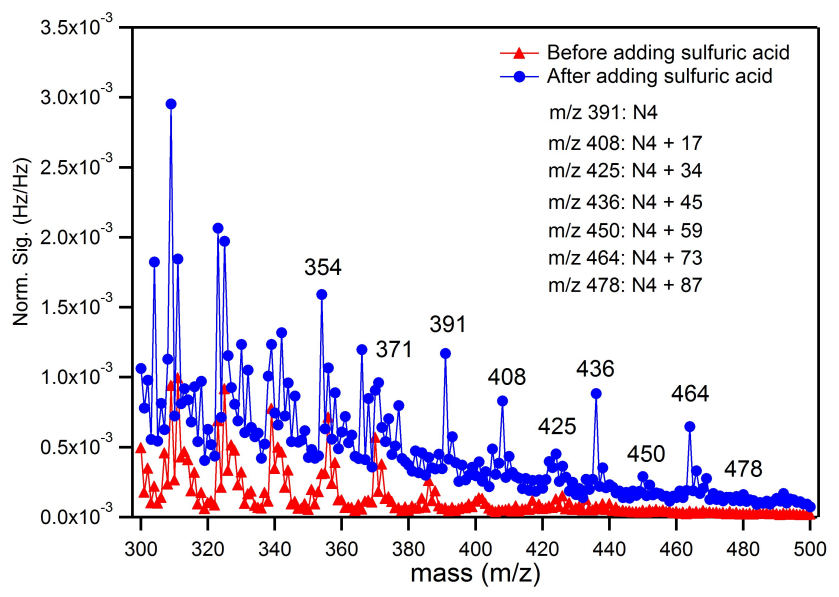

Fig. 2. Comparison of typical spectral scan (negative ions) from $\mathrm{m} / \mathrm{z}, 300-500 \mathrm{amu}$ between before (red) and after (blue) addition of $\sim 3 \times 10^{8} \mathrm{~cm}^{-3}$ sulfuric acid into the Cluster CIMS inlet. The residence time is $\sim 9 \mathrm{~s}$. The peaks corresponding to $\mathrm{m} / \mathrm{z}, 354$ and 371 are possibly some sulfur related compounds. Peak of $m / z, 391$ is assigned to be tetramer (N4) and $m / z 408,425$, are clusters containing $4 \mathrm{H}_{2} \mathrm{SO}_{4}$ molecules plus one or two ammonia molecules, respectively. Peaks corresponding to $m / z 436,450,464,478$ are clusters containing $4 \mathrm{H}_{2} \mathrm{SO}_{4}$ molecules plus one amine molecule. The masses of the amines are 45, 59, 73, and 87 amu respectively. Norm. Sig. is the individual signal divided by the total signal, summing over the reagent ions $(\mathrm{m} / \mathrm{z}, 125$ and 188). Measurements were carried out at the Foothills laboratory of NCAR in Boulder, Colorado.

tetramer $\mathrm{HSO}_{4}^{-} \cdot\left(\mathrm{H}_{2} \mathrm{SO}_{4}\right)_{3}$. Mass peaks corresponding to clusters containing four $\mathrm{H}_{2} \mathrm{SO}_{4}$ molecules plus one amine molecule were clearly distinguished from their backgrounds (e.g. $m / z 436,450,464)$. The indirectly inferred molecular weights of amines in the observed clusters are 45, 59, $73 \mathrm{amu}$, corresponding to dimethylamine or ethylamine (C2), trimethylamine or its isomer (C3), and amines containing four carbons (C4), respectively. These peaks were not observed before adding sulfuric acid and they were unambiguously observed only after the addition of elevated concentrations of sulfuric acid.

Further experimental evidence, obtained by varying the residence times for the neutral clusters- amine reactions from 3 to $9 \mathrm{~s}$, shows that the sulfuric acid-amine ion clusters detected with the Cluster CIMS result from ionization of neutral clusters containing both sulfuric acid and amines rather than from ion-induced clustering of sulfuric acid ion clusters with amines. Figure 3 shows concentrations of sulfuric acid-amine or sulfuric acid-ammonia clusters versus the concentration of total size 4 clusters (a sum of sulfuric acidammonia/amine clusters and sulfuric acid tetramers) with two residence times ( 3 and $9 \mathrm{~s}$ ) but the same ion reaction time $(0.6 \mathrm{~s})$. The slopes of these curves are indicative of the extent to which the sulfuric acid tetramer is converted to sulfuric acid-ammonia or sulfuric acid-amine clusters. The conver- sions of the tetramer to the above two types of clusters are comparable for the short residence time ( $3 \mathrm{~s})$. However, for the longer residence time $(9 \mathrm{~s})$ concentrations of the aminecontaining tetramer were much higher than those containing ammonia. For the $3 \mathrm{~s}$ residence time, the average percentages of sulfuric acid-ammonia and sulfuric acid-amine clusters are $37 \pm 10 \%$ and $30 \pm 8 \%(2 \sigma)$ respectively of all size 4 clusters. For the $9 \mathrm{~s}$ reaction time, these percentages are $24 \pm 6 \%$ and $53 \pm 7 \%(2 \sigma)$. This also indicates that the longer the interaction between sulfuric acid and amines, the more conversion of the tetramer to sulfuric acid-amine clusters. The percentage of ammonia clusters in the total size 4 clusters decreases while that of sulfuric acid-amine clusters increases for the longer residence time, implying that amines might displace ammonia in the sulfuric acid-ammonia clusters. This is consistent with the observations by Bzdek et al. (2010a, b). The decrease of both tetramer and ammonia cluster ratios and the increase of the total amine cluster ratio also imply that ammonia is more susceptible to loss than amines from their corresponding clusters upon ionization and analysis. By using two different residence times and keeping the ion reaction time fixed, the conversion ratios are distinctly different for converting the tetramer to sulfuric acid-amine clusters. Furthermore, these results confirm that the observed ion clusters do not arise from ion-induced clustering, otherwise these ratios should be independent of the residence times for a fixed ion reaction time.

SASA experiments were also carried out during the impact of the plume from a nearby coal-fired power plant, which already contained significantly elevated concentrations of sulfuric acid (Zhao et al., 2010). Figure 4 shows the temporal intensity profile for the individual sulfuric acid-amine clusters, along with the monomer and tetramer, all normalized to the reagent ions (sum of $m / z 125$ and $m / z$ 188). Before adding sulfuric acid (at 14:15 local US mountain time on 18 June 2010, $t=14: 15$ in Fig. 4), the intensities for all the masses were not distinguishable from background levels. The background levels were subtracted when calculating the intensities after adding sulfuric acid. Since the background levels might change over time, selection of background levels before adding sulfuric acid and applying them to the period after sulfuric acid was added does introduce uncertainties. However, these uncertainties should be insignificant because the background counts for the sulfuric acid-amine clusters are usually below $10 \mathrm{~Hz}$, much smaller than those after adding sulfuric acid. Upon turning on the mercury lamp (with $\mathrm{SO}_{2}$ and water vapor added), sulfuric acid was instantly formed in the reactor and introduced to the inlet. The intensities of mass 160 and 391 peaks, corresponding to deprotonated monomers (N1) and tetramer (N4) respectively, were increased substantially above their background levels. The intensities of other sulfuric acid clusters (e.g. dimers and trimers) were also clearly above their background levels (not shown in the figure). This amplification of cluster concentrations above ambient levels resulted in the observation 


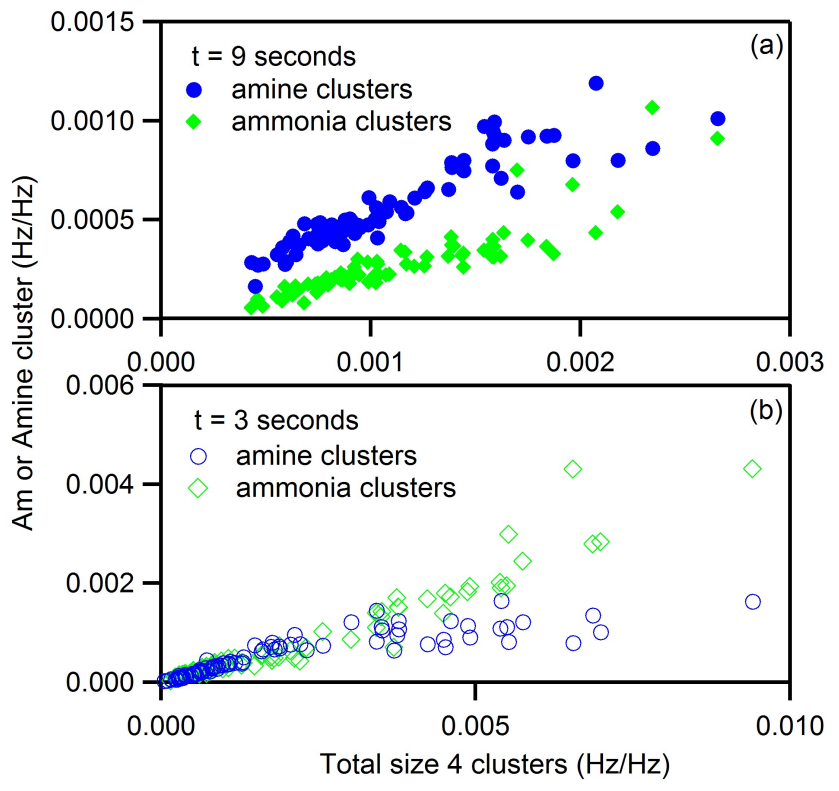

Fig. 3. Concentration of amine clusters (blue) (clusters contain both $4 \mathrm{H}_{2} \mathrm{SO}_{4}$ and 1 amine molecule and masses of amines are 45, 59, 73 or $87 \mathrm{amu}$ ) or ammonia clusters (green) (clusters contain both $4 \mathrm{H}_{2} \mathrm{SO}_{4}$ and 1-2 ammonia molecules) versus total concentration of size 4 clusters. The total size 4 clusters include sulfuric acid cluster $(\mathrm{m} / \mathrm{z}, 391)$, sulfuric acid-ammonia clusters $(\mathrm{m} / \mathrm{z}, 408$ and 425$)$, and sulfuric acid-amine clusters $(\mathrm{m} / \mathrm{z} 436,450,464$ and 478). Measurements were carried out at the Foothills laboratory of NCAR in Boulder, Colorado. (a) residence time $=9 \mathrm{~s}$ (solid); (b) residence time $=3 \mathrm{~s}$ (open).

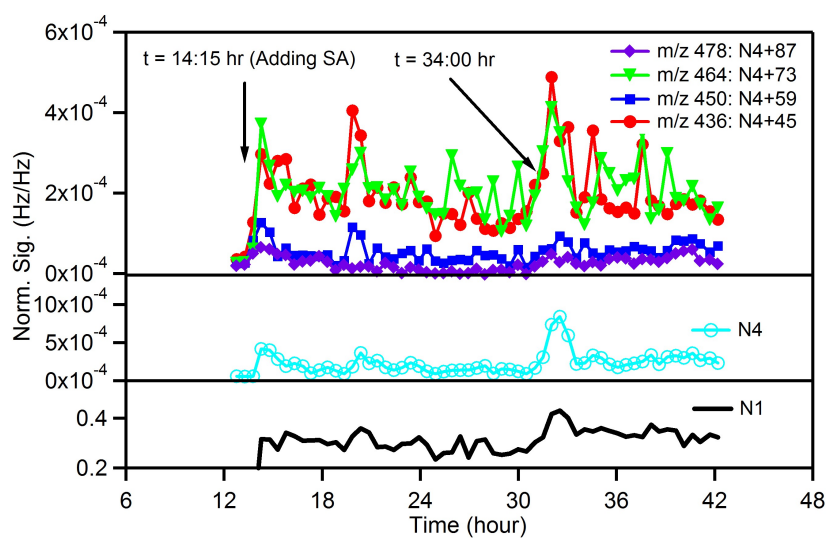

Fig. 4. Temporal profile of the sulfuric acid-amine clusters during the experiment period of 18 June-19 June 2010 (setting 00:00 a.m. local US mountain time 18 June as $0 \mathrm{~h}$ ), along with sulfuric acid tetramer (N4) and monomers (N1), measured at the Foothills laboratory of NCAR in Boulder, Colorado. Intensities of all the signals were divided by sum of intensities of reagent ions (i.e. $\mathrm{m} / \mathrm{z}, 125$ and 188). of sulfuric acid-amine clusters (Figs. 2 and 4). The intensities of two sulfuric acid-amine clusters $(\mathrm{m} / \mathrm{z}, 436$ and 464) were much higher than those of the other two $(\mathrm{m} / \mathrm{z} 450$ and 478), suggesting that their ambient concentrations were significantly higher. At around 10:00 a.m. local US mountain time on 19 June ( $t=34: 00 \mathrm{~h}$ in Fig. 4), a $\mathrm{SO}_{2}$ plume intercepted the measurement site, bringing extra sulfuric acid and its clusters. Interestingly, the intensities of the sulfuric acidamine clusters increased dramatically due to the increase of both sulfuric acid and the tetramer concentrations, indicating that they were formed in the inlet downstream of the location where sulfuric acid was added to the sampled air (Fig. 1).

Plots of normalized amine cluster intensities versus normalized tetramer intensity showed good correlations between sulfuric acid-amine clusters and the tetramer (Fig. 5). For example, correlation coefficients were $0.72,0.68,0.71$ and 0.51 between sulfuric acid-amine clusters $(\mathrm{m} / \mathrm{z}$ 436, 450, 464 and 478) and the tetramer, respectively. This indicates that the observed signals corresponding to sulfuric acid-amine clusters originate from tetramer or sulfuric acid, but not from other interfering compounds. Under experimental conditions, the observed ion clusters $\mathrm{HSO}_{4}^{-} \cdot\left(\mathrm{H}_{2} \mathrm{SO}_{4}\right)_{3}(\mathrm{~m} / \mathrm{z} 391)$ may result from ionization of neutral tetramers containing $\mathrm{H}_{2} \mathrm{SO}_{4}$ only (plus several $\mathrm{H}_{2} \mathrm{O}$ ), or there are also contributions from ammonia or amine tetramer clusters that lose the base molecules upon ionization and analysis. The contributions of the above two processes to $m / z 391$ depend on the residence time, the concentrations of the base molecules, and the relative stabilities of the sulfuric acid-ammonia or amine clusters. Hence, the measured concentrations of the sulfuric acid-amine clusters represent the lower limit values of the corresponding neutral clusters. Measurements of ammonia and amine concentrations are needed in the future in order to better understand the mechanisms and constrain the kinetic parameters for the formation of sulfuric acid-ammonia or amine clusters.

Additional experiments were carried out to confirm that the amines taken up by clusters were from ambient air and were not inadvertently added with reactants used for signal amplification $\left(\mathrm{H}_{2} \mathrm{O}, \mathrm{SO}_{2}, \mathrm{O}_{2}, \mathrm{~N}_{2}\right.$, etc.; Fig. 1). In these experiments, the flow reactor was directly connected to a well-sealed inlet of the Cluster CIMS. This inlet draws gases from the reactor via a half inch Teflon tubing by a diaphragm pump. The total flow through the reactor is about $3.5 \mathrm{lpm}$ and the resulting $5 \mathrm{~s}$ residence time in the reactor is in the range of the residence times used in the SASA experiments. The $\mathrm{SO}_{2} / \mathrm{O}_{2}$ flow was introduced in the same way as in the SASA experiments, and several sets of experiments were carried out. About $1 \mathrm{lpm}$ pure $\mathrm{N}_{2}$ flow from a liquid nitrogen tank was bubbled through the deionized water and subsequently combined with the $2.5 \mathrm{lpm}$ pure $\mathrm{N}_{2}$ flow that provided the balance of the flow. After turning on the lamp, peaks corresponding to the sulfuric acid-amine clusters observed in the ambient air SASA experiments $(m / z 436,450,464$, and 478; Fig. 2) were not detected (Fig. 6a). Experiments were 


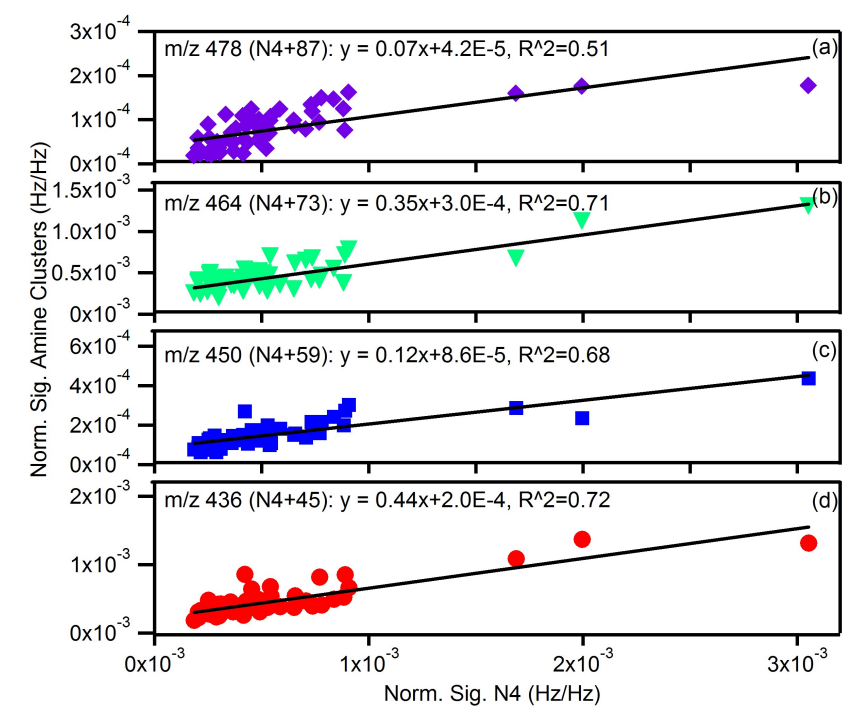

Fig. 5. Correlation of individual amine concentration with sulfuric acid tetramer (N4) (normalized) from measurements in Fig. 4.

also done using zero air from a pure air generator (Aadco 737, Aadco Instruments Inc) as the carrier gas instead of the pure $\mathrm{N}_{2}$. Again, sulfuric acid monomer, dimer, trimer and tetramer were observed but not sulfuric acid-amine clusters (Fig. 6b). However, when the same flow rate (about $3.5 \mathrm{lpm}$ ) of room air was drawn through the reactor, the sulfuric acidamine clusters (especially $\mathrm{m} / \mathrm{z}$ 464) were detected in addition to sulfuric acid monomer and its clusters (Fig. 6c). Sulfuric acid concentrations in the above experiments were estimated to be about $5 \times 10^{8} \mathrm{~cm}^{-3}$. This experiment clearly demonstrates that the amine-tetramer clusters observed in the ambient air SASA experiments were from amines in the ambient air and not from amine contamination associated with the addition of sulfuric acid.

\subsection{First measurements of ambient sulfuric acid-amine clusters and their correlation with sulfuric acid tetramer and nanoparticles}

Section 3.1 described the results of the semi-ambient signal amplification measurements, where sulfuric acid was added to sampled air to increase signals measured with the Cluster CIMS. In this section we describe our first attempt to directly measure neutral amine-containing clusters at ambient levels. The protocol is to measure a limited number of selected ions including deprotonated sulfuric acid clusters and clusters containing both sulfuric acid and various amines, with a cycle time of $5 \mathrm{~min}$. These cluster concentrations were compared with concentrations of $1-2 \mathrm{~nm}$ particles (nano $\mathrm{CN}$ ) measured with the DEG SMPS.

A temporal profile of several different measurements is shown in Fig. 7, which includes a relatively strong nucleation event. The nucleation event started at around 10:00 a.m. local daylight saving time (LDT) as evidenced by the dramatic

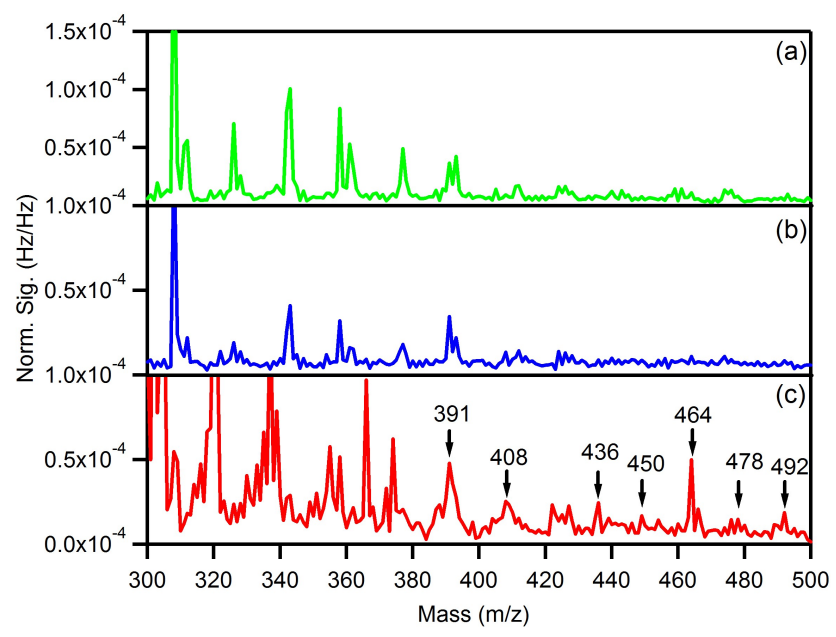

Fig. 6. Comparison of spectral scan from $m / z, 300-500$ amu for generating sulfuric acid clusters using different carrier gases: (a) pure $\mathrm{N}_{2}$ from liquid nitrogen tank; (b) zero air from pure air generator; (c) room air. For (a) and (b), water vapor was introduced into the reactor by bubbling about $1 \mathrm{lpm}$ of gas through the deionized water. For (c), water vapor was from room air and no additional water was added into the reactor. For the experimental set-up, see the text for details.

increase of $\mathrm{SO}_{2}$, ultrafine particles, and sulfuric acid concentrations, and ended at around 14:00. As described in Zhao et al. (2010), nucleation events are observed at this measurement location when the wind transports $\mathrm{SO}_{2}$ emissions from the coal-fired power plant located at about $4 \mathrm{~km}$ southeast of the site. On 1 September 2010, the wind blew from the west before 09:30 a.m. LDT and it changed to SE/E after that, bringing high concentrations of $\mathrm{SO}_{2}$ and $\mathrm{H}_{2} \mathrm{SO}_{4}$ (Fig. 7a and c), presumably associated with the power plant plume. At about 10:50 a.m., the wind turned to W/NW (Fig. 7b) and the $\mathrm{SO}_{2} / \mathrm{H}_{2} \mathrm{SO}_{4}$ concentrations dropped rapidly. At around 12:30, the $\mathrm{SO}_{2}$ concentration decreased to the background level, while $\mathrm{H}_{2} \mathrm{SO}_{4}$ concentrations remained elevated until around 14:00. Figure 7e shows data for concentrations of tetramer and tetramer-amine clusters, both normalized to $\mathrm{m} / \mathrm{z} 125$, the reagent ion. Elevated concentrations of tetramer were observed during the event, but on this day its peak was delayed by about $1 \mathrm{~h}$ relative to the $\mathrm{SO}_{2}$ peak concentration. The sulfuric acid-amine clusters correlated reasonably well with the tetramer and were above the background levels during the event period (10:00-14:00), although cluster signals were low and subject to error due to interferences from other compounds at the same nominal mass. The intensities corresponding to the sulfuric acid-amine clusters were observed to continuously rise from 07:30 to 09:30, before the event occurred. The $\mathrm{H}_{2} \mathrm{SO}_{4}$ concentration steadily increased due to photooxidation of $\mathrm{SO}_{2}$ after sunrise. During the period when plume concentrations were highest (from about 09:30 to 11:00), the intensities of sulfuric acid-amine clusters were 


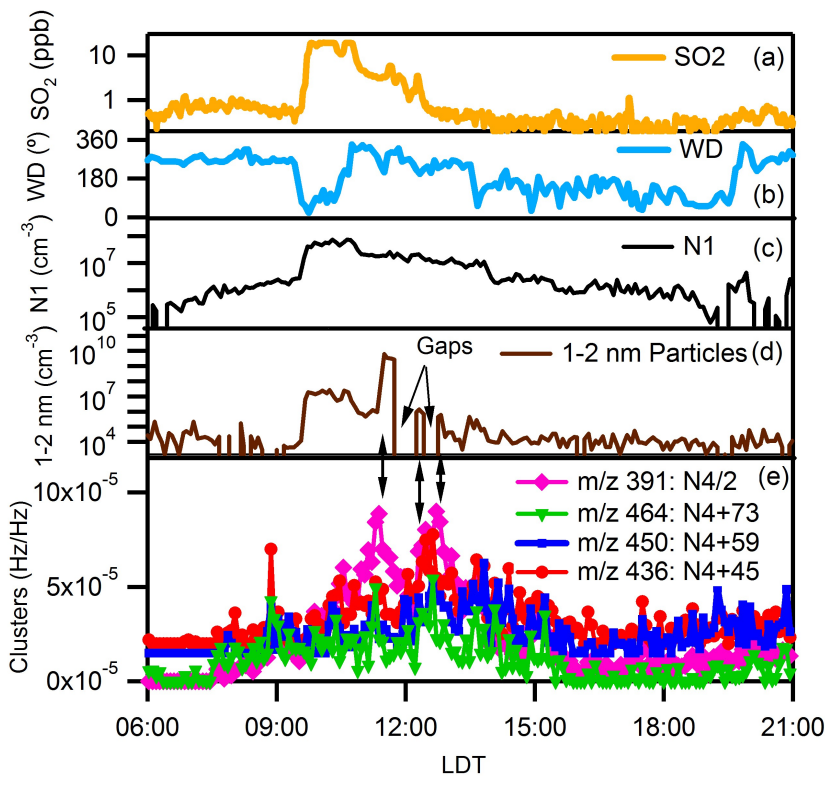

Fig. 7. Ambient measurements on 1 September 2010 at the NCAR Foothills Laboratory in Boulder, Colorado: (a) concentration of $\mathrm{SO}_{2}$ (yellow); (b) wind direction (WD, in degree) (light blue); (c) concentration of monomers in logarithm scale $\left(\mathrm{N} 1\right.$ in $\left.\mathrm{cm}^{-3}\right)$ (black); (d) concentrations (uncorrected) of nanoparticles in a size range of 1-2 nm measured from DEG SMPS(dark purple); (e) signals of the sulfuric acid-amine clusters (N4+45/59/73) and sulfuric acid tetramer (N4, shown in half intensity), divided by the reagent ion (i.e. $\mathrm{m} / \mathrm{z}$ 125). The $\mathrm{m} / \mathrm{z} 436$ and 450 curves were shifted up by $2 \times 10^{-5}$ and $1.5 \times 10^{-5}$ respectively for easier view. LDT is local daylight saving time.

not significantly elevated. After 11:00 a.m., concentrations of both the tetramer and the sulfuric acid-amine clusters increased significantly, and these high levels continued when the wind from the Rocky Mountains (i.e. westerly and southwesterly flow) was observed. The wind switched to SE and the sulfuric acid-amine cluster signals began to decline after 13:30. The reason that the amine cluster signals are dependent on the wind direction is not known. It is possible that westerly air mass brings higher interferences (from other organic compounds rather than the sulfuric acid-amine clusters) than the air flow from E/SE. However, some correlations between the clusters and the nanoparticle formation were found, indicating that the formation of these clusters and nanoparticles might lag behind the formation of sulfuric acid in this particular case, as discussed below.

Figure 7e shows that several sulfuric acid-amine cluster peaks, especially the $m / z 464(\mathrm{~N} 4+73)$ cluster, varied along with that of the tetramer. Those peaks, however, exhibited rapid "spikes", in contrast to the tetramer which varied more smoothly with time. The "spikes" feature is likely due to much lower concentrations of these sulfuric acidamine clusters and hence the poor counting statistics (less than 100 counts in an integration time of $8 \mathrm{~s}$ ). Only poor correlation was found between sulfuric acid-amine clusters and tetramer if all the measured data during the event period (10:00-14:00) are included probably due to the poor counting statistics. However, as shown in Fig. 8, some correlations are found if only peak concentrations of amine clusters and tetramer during the nucleation period are selected for correlation. The best correlation was seen for the $(\mathrm{N} 4+73)$ cluster (Fig. 8a) that had a relatively high counting rate. This is consistent with observations from the SASA experiments (Fig. 5). Additional evidence of delay of cluster formation can be found in the DEG measurements (Fig. 7d). During the nucleation period, the concentrations of nanoparticles from 1-2 nm were significantly elevated compared to those before and after the event. High concentrations of 1-2 nm particles between around 11:15-11:45 were observed, with peaks in the total concentration of $1-2 \mathrm{~nm}$ particles (indicated by a double-ended arrows between Fig. 7d and e) corresponding to high intensities of tetramer (sulfuric acid-amine clusters) during the same period. Another less intense band of about 1-2 nm particles around 12:00-12:45 seem to correspond to a high intensity of the tetramer as well. Note that two background tests were performed between 11:50 to 12:40 (the blank gaps in the 1-2 nanometer particle plot, Fig. 7d) so that the second comparison is not straightforward. Because of these data gaps, direct correlation of concentrations of 1$2 \mathrm{~nm}$ particles and the sulfuric acid-amine clusters or the total clusters containing four $\mathrm{H}_{2} \mathrm{SO}_{4}$ in a way similar to that for tetramer and the sulfuric acid-amine clusters is difficult. Clearly, more ambient measurements under both high sulfuric acid and amine concentrations, along with measurements of all gas phase precursors, are needed in order to better constrain the correlation between sulfuric acid-amine clusters and the nanoparticles.

\subsection{Formation mechanisms of sulfuric acid-amine clusters in the atmosphere}

As discussed in Sect. 3.1, the sulfuric acid-amine clusters can be formed either via reactions of sulfuric acid clusters with amines or displacement of ammonia by amines in the sulfuric acid-ammonia clusters. In either case, the concentrations of the sulfuric acid-amine clusters are dependent on concentrations of both sulfuric acid clusters (hence sulfuric acid) and amines. The neutral sulfuric acid-amine clusters can be formed either directly from reactions of sulfuric acid/sulfuric acid clusters with amines (Scheme 1) or from displacement of ammonia by amines in the sulfuric acid-ammonia clusters (Scheme 2) as shown below for the formation of sulfuric acid-amine clusters containing $4 \mathrm{H}_{2} \mathrm{SO}_{4}$ molecules. As discussed in Zhao et al. (2010), the Cluster CIMS detects core ions in the form of $\mathrm{HSO}_{4}^{-} \cdot\left(\mathrm{H}_{2} \mathrm{SO}_{4}\right)_{n}(n \leq 4)$ from which other stabilizing compounds may have been lost, especially for clusters smaller than tetramers. Bare sulfuric acid clusters such as $\left(\mathrm{H}_{2} \mathrm{SO}_{4}\right)_{n}(n \geq 3)$ (with $\left.\mathrm{H}_{2} \mathrm{O}\right)$ are not likely present in the atmosphere to any significant extent due to their strong 


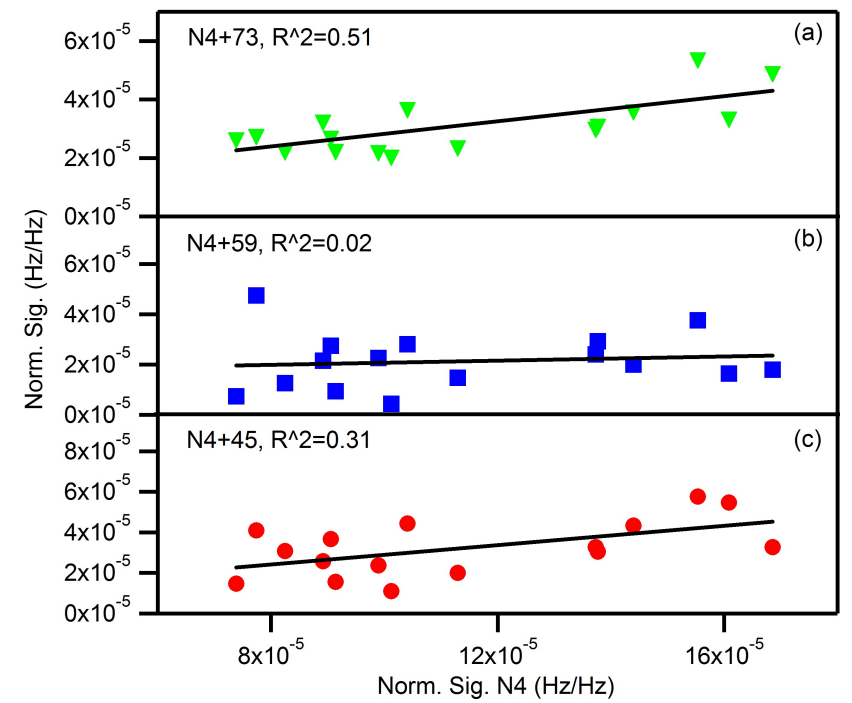

Fig. 8. Correlation of individual amine cluster concentration with sulfuric acid tetramer (N4) (normalized) for selecting peaks only during the event period (10:00-14:00) from Fig. 7.

binding capability with other compounds, long interaction times between those clusters and ambient trace gases, and their relatively short lifetime against thermal dissociation. Hence in the presence of other compounds (e.g. amines), sulfuric acid clusters likely react with other species and incorporate them into the clusters via intermolecular interactions (e.g. hydrogen bonding). As shown in Scheme 1, a sulfuric acid-amine tetramer $\left(\mathrm{H}_{2} \mathrm{SO}_{4}\right)_{4}$. AMI can be formed via two sequential reactions of a dimer $\left(\mathrm{H}_{2} \mathrm{SO}_{4}\right)_{2}$. AMI with sulfuric acid. Formation of $\left(\mathrm{H}_{2} \mathrm{SO}_{4}\right)_{2}$. AMI is critical to the initiation of new nucleus production. In principle, it can be produced either by forming a complex $\mathrm{H}_{2} \mathrm{SO}_{4}$. AMI first (1-1), followed by reaction with $\mathrm{H}_{2} \mathrm{SO}_{4}(1-3)$, or directly between the dimer $\left(\mathrm{H}_{2} \mathrm{SO}_{4}\right)_{2}$ and amines (1-4). Which formation pathway is dominant is currently not understood. Formation of sulfuric acid-ammonia tetramers follows a similar reaction pattern (2-2 and 2-4). The sulfuric acid-amine clusters can also be formed from amine exchange of ammonia in the ammonium clusters, as shown by Bzdek et al. (2010a, b). This likely occurs after formation of the dimer $\left(\mathrm{H}_{2} \mathrm{SO}_{4}\right)_{2} \cdot \mathrm{AM}$ as shown in Scheme 2 for displacement of a $\mathrm{NH}_{3}$ by an amine (2-1, 2-3, and 2-5). The branching ratios for competitive reactions of sulfuric acid and its clusters with amines and with ammonia are determined by the kinetic processes in Scheme 1 and 2. Since a longer residence time favors formation of the cluster $\left(\mathrm{H}_{2} \mathrm{SO}_{4}\right)_{4}$. AMI for both pathways, simply varying the residence times cannot determine which mechanism is dominant. Note also that the proposed mechanisms in Schemes 1 and 2 represent the simplest possible formation pathways for the sulfuric acid-amine clusters by assuming that the clusters grow and evaporate only by monomer addition and evaporation. Direct experimental evidence for the stabilities of most of the neutral clusters is still currently

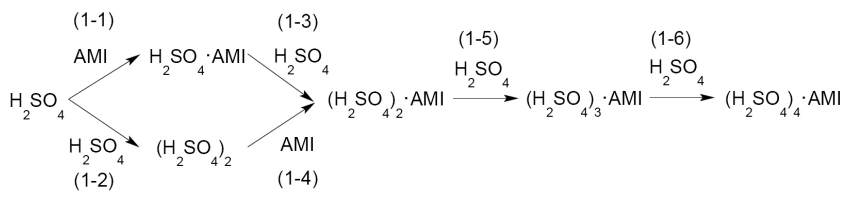

Scheme 1. Direct formation from neutral sulfuric acid clusters (For simplification, water molecules are not included in the clusters; $\mathrm{AMI}=$ amine) .

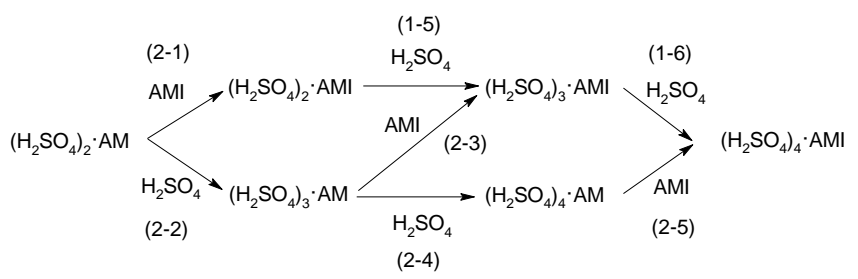

Scheme 2. Formation of sulfuric acid-amine tetramers from amine exchange (A simple example is given for displacement of $\mathrm{NH}_{3}$ by an amine; $\mathrm{AM}=$ ammonia $)$.

lacking. Clearly, better controlled experiments and more ambient measurements are needed in order to evaluate the role of amines and ammonia in stabilizing sulfuric acid clusters and their roles in new particle formation.

\section{Summary and conclusions}

Measurements of atmospheric clusters containing both $\mathrm{H}_{2} \mathrm{SO}_{4}$ and amines in the core ions are extremely difficult because these clusters exist in very low concentrations and amines are likely lost from the core ions upon ionization, especially for ions containing fewer than $4 \mathrm{H}_{2} \mathrm{SO}_{4}$ molecules. The detection of neutral sulfuric acid-amine clusters is hence largely dependent on the stability of their corresponding cluster ions. Semi-ambient signal amplification experiments were carried out to look for the effects of amines on nucleation. Upon addition of sulfuric acid to ambient air, a series of new peaks were clearly observed, corresponding to core ions containing only $\mathrm{H}_{2} \mathrm{SO}_{4}$, and both $\mathrm{H}_{2} \mathrm{SO}_{4}$ and amine/ammonia. This signal amplification technique was employed for the first time to identify neutral clusters containing both $\mathrm{H}_{2} \mathrm{SO}_{4}$ and amines that have been hypothesized to play important roles in new particle formation and growth. Observation of neutral sulfuric acid-amine clusters sampled directly from Boulder air was also confirmed experimentally for the first time. These measurements show that the neutral sulfuric acid-amine clusters can be chemically ionized and are relatively stable upon ionization once they grow large enough. Our observations showed that neutral clusters containing 4 or more $\mathrm{H}_{2} \mathrm{SO}_{4}$ molecules are large enough to retain at least one amine, similar to sulfuric acid-ammonia clusters. The relative abundances of the sulfuric acid-amine clusters were found to vary and the two most abundant sulfuric 
acid-amine clusters were always those containing a C2- or C4-amine at this particular measurement site. Measurements of amine concentrations are needed in order to understand the correlation between concentration distributions of the amine clusters and abundances of the individual amine.

With the addition of elevated concentrations of $\mathrm{H}_{2} \mathrm{SO}_{4}$ in the Cluster CIMS inlet, it was much easier to distinguish the neutral sulfuric acid-amine clusters from the background spectra. This technique also facilitates an examination of the correlation between sulfuric acid clusters and sulfuric acidamine clusters. Good correlations further confirmed that signals corresponding to the neutral sulfuric acid-amine clusters originate from sulfuric acid or its clusters, not from other interference compounds. Combined with the time-dependent distributions between sulfuric acid-amine clusters and ammonia clusters, the formation of the sulfuric acid-amine clusters was found to be from reactions of the amines with neutral clusters rather than from ion-induced clustering of sulfuric acid cluster ions with amines. Since ammonia concentrations are generally higher than those of amines, results from measurements from various residence times also showed that one formation mechanism involves displacement of ammonia by amines in sulfuric acid-ammonia clusters. The importance of amines vs. ammonia in new particle formation and growth is dependent on the stabilization ability of the amine and ammonia to sulfuric acid clusters and the abundances of the amines and ammonia in the atmosphere.

The first measurements of ambient neutral sulfuric acidamine clusters during nucleation event periods were made using the mass identification of sulfuric acid-amine clusters from the SASA measurements. The measurements focused on sulfuric acid clusters, sulfuric acid-amine/ammonia clusters, along with sulfuric acid monomer and a few other masses. The results showed that signals of the sulfuric acidamine clusters correlated reasonably to those of the tetramer. However, with a typical sulfuric acid concentration below $1 \times 10^{8} \mathrm{~cm}^{-3}$, measurements of sulfuric acid-amine clusters suffered from high interferences from other compounds, mainly organic compounds. As shown in the SASA measurements, a sulfuric acid concentration above $10^{8} \mathrm{~cm}^{-3}$ during nucleation events is necessary in order to take full advantage of this signal amplification technique. Under a relatively high concentration of sulfuric acid (hence its clusters), the sulfuric acid-amine clusters can be more definably distinguished from their corresponding backgrounds. Also, the correlations between sulfuric acid-amine clusters and 1-2 nm particles can be statistically more easily explored with a proper measurement protocol between the Cluster CIMS and DEG measurements. Sulfur-rich environments such as Atlanta and Pittsburgh (with ambient sulfuric acid concentrations sometimes above $10^{8} \mathrm{~cm}^{-3}$ ) can be ideal locations for such measurements. Clearly, more ambient measurements are needed in the future in order to better understand the roles of amines and ammonia in formation and growth of atmospheric neutral nucleating clusters.
Acknowledgements. This work was funded by NSF award ATM0506674. PHM was supported by a Guggenheim Fellowship. The authors acknowledge Sasha Madronich and Chris Cantrell for valuable comments. The National Center for Atmospheric Research is sponsored by the National Science Foundation.

Edited by: M. Ammann

\section{References}

Ball, S. M., Hanson, D. R., Eisele, F. L., and McMurry, P. H.: Laboratory studies of particle nucleation: Initial results for $\mathrm{H}_{2} \mathrm{SO}_{4}$, $\mathrm{H}_{2} \mathrm{O}$, and $\mathrm{NH}_{3}$ vapors, J. Geophys. Res., 104, 23709-23718, 1999.

Barsanti, K. C., McMurry, P. H., and Smith, J. N.: The potential contribution of organic salts to new particle growth, Atmos. Chem. Phys., 9, 2949-2957, doi:10.5194/acp-9-2949-2009, 2009.

Benson, D. R., Young, L. H., Kameel, F. R., and Lee, S. H.: Laboratory-measured nucleation rates of sulfuric acid and water binary homogeneous nucleation from the $\mathrm{SO}_{2}+\mathrm{OH}$ reaction, Geophys. Res. Lett., 35, L11801, doi:10.1029/2008g1033387, 2008.

Benson, D. R., Erupe, M. E., and Lee, S. H.: Laboratorymeasured $\mathrm{H}_{2} \mathrm{SO}_{4}-\mathrm{H}_{2} \mathrm{O}-\mathrm{NH}_{3}$ ternary homogeneous nucleation rates: Initial observations, Geophys. Res. Lett., 36, L15818, doi:10.1029/2009g1038728, 2009.

Benson, D. R., Erupe, M. E., Yu, J. H., Markovich, A., and Lee, S.-H.: Atmospheric homogeneous nucleation of $\mathrm{H}_{2} \mathrm{SO}_{4}$ and $\mathrm{H}_{2} \mathrm{O}$, Atmos. Chem. Phys. Discuss., 10, 29051-29073, doi:10.5194/acpd-10-29051-2010, 2010.

Berndt, T., Boge, O., Stratmann, F., Heintzenberg, J., and Kulmala, M.: Rapid formation of sulfuric acid particles at nearatmospheric conditions, Science, 307, 698-700, 2005.

Berndt, T., Boge, O., and Stratmann, F.: Formation of atmospheric $\mathrm{H}_{2} \mathrm{SO}_{4} / \mathrm{H}_{2} \mathrm{O}$ particles in the absence of organics: A laboratory study, Geophys. Res. Lett., 33, L15817, doi:10.1029/2006g1026660, 2006.

Berndt, T., Stratmann, F., Sipilä, M., Vanhanen, J., Petäjä, T., Mikkilä, J., Grüner, A., Spindler, G., Lee Mauldin III, R., Curtius, J., Kulmala, M., and Heintzenberg, J.: Laboratory study on new particle formation from the reaction $\mathrm{OH}+\mathrm{SO}_{2}$ : influence of experimental conditions, $\mathrm{H}_{2} \mathrm{O}$ vapour, $\mathrm{NH}_{3}$ and the amine tert-butylamine on the overall process, Atmos. Chem. Phys., 10, 7101-7116, doi:10.5194/acp-10-7101-2010, 2010.

Bzdek, B. R., Ridge, D. P., and Johnston, M. V.: Size-Dependent Reactions of Ammonium Bisulfate Clusters with Dimethylamine, J. Phys. Chem. A, 114, 11638-11644, 2010a.

Bzdek, B. R., Ridge, D. P., and Johnston, M. V.: Amine exchange into ammonium bisulfate and ammonium nitrate nuclei, Atmos. Chem. Phys., 10, 3495-3503, doi:10.5194/acp-10-3495-2010, 2010b.

Cadle, S. H. and Mulawa, P. A.: Low-molecular weight aliphaticamines in exhaust from catalyst-equipped cards, Environ. Sci Technol., 14, 718-723, 1980.

Eisele, F. L. and Hanson, D. R.: First measurement of prenucleation molecular clusters, J. Phys. Chem. A, 104, 830-836, 2000.

Eisele, F. L. and Tanner, D. J.: Measurement of the gas-phase concentration of $\mathrm{H}_{2} \mathrm{SO}_{4}$ production and loss in the atmosphere, $\mathrm{J}$. 
Geophys. Res., 98, 9001-9010, 1993.

Eisele, F. L., Lovejoy, E. R., Kosciuch, E., Moore, K. F., Mauldin, R. L., Smith, J. N., McMurry, P. H., and Iida, K.: Negative atmospheric ions and their potential role in ion-induced nucleation, J. Geophys. Res., 111, D04305, doi:10.1029/2005jd006568, 2006.

Erupe, M. E., Viggiano, A. A., and Lee, S.-H.: The effect of trimethylamine on atmospheric nucleation involving $\mathrm{H}_{2} \mathrm{SO}_{4}$, Atmos. Chem. Phys., 11, 4767-4775, doi:10.5194/acp-11-47672011, 2011.

Facchini, M. C., Decesari, S., Rinaldi, M., Carbone, C., Finessi, E., Mircea, M., Fuzzi, S., Moretti, F., Tagliavini, E., Ceburnis, D., and O'Dowd, C. D.: Important Source of Marine Secondary Organic Aerosol from Biogenic Amines, Environ. Sci. Technol., 42, 9116-9121, 2008.

Ge, X. L., Wexler, A. S., and Clegg, S. L.: Atmospheric amines Part I. A review, Atmos. Environ., 45, 524-546, 2010a.

Ge, X. L., Wexler, A. S., and Clegg, S. L.: Atmospheric amines Part II. Thermodynamic properties and gas/particle partitioning, Atmos. Environ., 45, 561-577, 2010b.

Ghan, S. J., Easter, R. C., Chapman, E. G., Abdul-Razzak, H., Zhang, Y., Leung, L. R., Laulainen, N. S., Saylor, R. D., and Zaveri, R. A.: A physically based estimate of radiative forcing by anthropogenic sulfate aerosol, J. Geophys. Res., 106, 52795293, 2001.

Hanson, D. R. and Eisele, F. L.: Measurement of prenucleation molecular clusters in the $\mathrm{NH}_{3}, \mathrm{H}_{2} \mathrm{SO}_{4}, \mathrm{H}_{2} \mathrm{O}$ system, J. Geophys. Res., 107, 4158, doi:10.1029/2001jd001100, 2002.

Hanson, D. R., McMurry, P. H., Jiang, J. K., Huey, G., and Tanner, D.: Ambient Pressure Proton Transfer mass spectrometry: detection of ammonia and amines, Environ. Sci. Technol., 45, 8881-8888, 2011.

Iida, K.: Atmospheric nucleation: development and application of nanoparticle measurements to assess the roles of ion-induced and neutral Processes, Ph.D. dissertation thesis, 188 pp., University of Minnesota, Minneapolis, 2008.

Iida, K., Stolzenburg, M., McMurry, P., Dunn, M. J., Smith, J. N., Eisele, F., and Keady, P.: Contribution of ion-induced nucleation to new particle formation: Methodology and its application to atmospheric observations in Boulder, Colorado, J. Geophys. Res., 111, D23201, doi:10.1029/2006jd007167, 2006.

Iida, K., Stolzenburg, M. R., McMurry, P. H., and Smith, J. N.: Estimating nanoparticle growth rates from sizedependent charged fractions: Analysis of new particle formation events in Mexico City, J. Geophys. Res., 113, D05207, doi:10.1029/2007jd009260, 2008.

Iida, K., Stolzenburg, M. R., and McMurry P. H.: Effect of Working Fluid on Sub-2 nm Particle Detection with a Laminar Flow Ultrafine Condensation Particle Counter, Aerosol Sci. Tech., 43, 81-96, 2009.

Jiang, J. K., Chen, M. D., Kuang, C. A., Attoui, M., and McMurry, P. H.: Electrical Mobility Spectrometer Using a Diethylene Glycol Condensation Particle Counter for Measurement of Aerosol Size Distributions Down to $1 \mathrm{~nm}$, Aerosol Sci. Tech., 45, 510 521, 2011a.

Jiang, J. K., Zhao, J., Chen, M. D., Eisele, F. L., Scheckman, J., Williams, B. J., Kuang, C. A., and McMurry, P. H.: First Measurements of Neutral Atmospheric Cluster and 1-2 nm Particle Number Size Distributions During Nucleation Events, Aerosol Sci. Tech., 45, II-V, 2011b.
Kerminen, V. M. and Kulmala, M.: Analytical formulae connecting the "real" and the "apparent" nucleation rate and the nuclei number concentration for atmospheric nucleation events, J. Aerosol Sci., 33, 609-622, 2002.

Kerminen, V. M., Lihavainen, H., Komppula, M., Viisanen, Y., and Kulmala, M.: Direct observational evidence linking atmospheric aerosol formation and cloud droplet activation, Geophys. Res. Lett., 32, L14803, doi:10.1029/2005g1023130, 2005.

Kirkby, J., Curtius, J., Almeida, J., Dunne, E., Duplissy, J., Ehrhart, S., Franchin, A., Gagne, S., Ickes, L., Kurten, A., Kupc, A., Metzger, A., Riccobono, F., Rondo, L., Schobesberger, S., Tsagkogeorgas, G., Wimmer, D., Amorim, A., Bianchi, F., Breitenlechner, M., David, A., Dommen, J., Downard, A., Ehn, M., Flagan, R. C., Haider, S., Hansel, A., Hauser, D., Jud, W., Junninen, H., Kreissl, F., Kvashin, A., Laaksonen, A., Lehtipalo, K., Lima, J., Lovejoy, E. R., Makhmutov, V., Mathot, S., Mikkila, J., Minginette, P., Mogo, S., Nieminen, T., Onnela, A., Pereira, P., Petaja, T., Schnitzhofer, R., Seinfeld, J. H., Sipila, M., Stozhkov, Y., Stratmann, F., Tome, A., Vanhanen, J., Viisanen, Y., Vrtala, A., Wagner, P. E., Walther, H., Weingartner, E., Wex, H., Winkler, P. M., Carslaw, K. S., Worsnop, D. R., Baltensperger, U., and Kulmala, M.: Role of sulphuric acid, ammonia and galactic cosmic rays in atmospheric aerosol nucleation, Nature, 476, 429-433, doi:10.1038/nature10343, 2011.

Kuang, C., McMurry, P. H., McCormick, A. V., and Eisele, F. L.: Dependence of nucleation rates on sulfuric acid vapor concentration in diverse atmospheric locations, J. Geophys. Res., 113, D10209, doi:10.1029/2007jd009253, 2008.

Kuang, C., McMurry, P. H., and McCormick, A. V.: Determination of cloud condensation nuclei production from measured new particle formation events, Geophys. Res. Lett., 36, L09822, doi:10.1029/2009g1037584, 2009.

Kuang, C., Riipinen, I., Sihto, S.-L., Kulmala, M., McCormick, A. V., and McMurry, P. H.: An improved criterion for new particle formation in diverse atmospheric environments, Atmos. Chem. Phys., 10, 8469-8480, doi:10.5194/acp-10-8469-2010, 2010.

Kulmala, M., Pirjola, U., and Makela, J. M.: Stable sulphate clusters as a source of new atmospheric particles, Nature, 404, 66-69, 2000.

Kulmala, M., Vehkamaki, H., Petaja, T., Dal Maso, M., Lauri, A., Kerminen, V. M., Birmili, W., and McMurry, P. H.: Formation and growth rates of ultrafine atmospheric particles: a review of observations, J. Aerosol Sci., 35, 143-176, 2004.

Kulmala, M., Lehtinen, K. E. J., and Laaksonen, A.: Cluster activation theory as an explanation of the linear dependence between formation rate of $3 \mathrm{~nm}$ particles and sulphuric acid concentration, Atmos. Chem. Phys., 6, 787-793, doi:10.5194/acp-6-787-2006, 2006.

Kulmala, M., Riipinen, I., Sipila, M., Manninen, H. E., Petaja, T., Junninen, H., Dal Maso, M., Mordas, G., Mirme, A., Vana, M., Hirsikko, A., Laakso, L., Harrison, R. M., Hanson, I., Leung, C., Lehtinen, K. E. J., and Kerminen, V. M.: Toward direct measurement of atmospheric nucleation, Science, 318, 89-92, doi:10.1126/science.1144124, 2007.

Kurtén, T., Loukonen, V., Vehkamäki, H., and Kulmala, M.: Amines are likely to enhance neutral and ion-induced sulfuric acid-water nucleation in the atmosphere more effectively than ammonia, Atmos. Chem. Phys., 8, 4095-4103, doi:10.5194/acp8-4095-2008, 2008. 
Laaksonen, A., Hamed, A., Joutsensaari, J., Hiltunen, L., Cavalli, F., Junkermann, W., Asmi, A., Fuzzi, S., and Facchini, M. C.: Cloud condensation nucleus production from nucleation events at a highly polluted region, Geophys. Res. Lett., 32, L06812, doi:10.1029/2004g1022092, 2005.

Lehtinen, K. E. J., Dal Maso, M., Kulmala, M., and Kerminen, V. M.: Estimating nucleation rates from apparent particle formation rates and vice versa: Revised formulation of the KerminenKulmala equation, J. Aerosol Sci., 38, 988-994, 2007.

Lihavainen, H., Kerminen, V. M., Komppula, M., Hatakka, J., Aaltonen, V., Kulmala, M., and Viisanen, Y.: Production of "potential" cloud condensation nuclei associated with atmospheric new-particle formation in northern Finland, J. Geophys. Res., 108, 4782, doi:10.1029/2003jd003887, 2003.

Lovejoy, E. R. and Curtius, J.: Cluster ion thermal decomposition (II): Master equation modeling in the low-pressure limit and falloff regions. Bond energies for $\mathrm{HSO}_{4}^{-}\left(\mathrm{H}_{2} \mathrm{SO}_{4}\right)_{(\mathrm{x})}\left(\mathrm{HNO}_{3}\right)_{(\mathrm{y})}, \mathrm{J}$. Phys. Chem. A, 105, 10874-10883, 2001.

Malloy, Q. G. J., Li Qi, Warren, B., Cocker III, D. R., Erupe, M. E., and Silva, P. J.: Secondary organic aerosol formation from primary aliphatic amines with $\mathrm{NO}_{3}$ radical, Atmos. Chem. Phys., 9, 2051-2060, doi:10.5194/acp-9-2051-2009, 2009.

Manninen, H. E., Nieminen, T., Asmi, E., Gagné, S., Häkkinen, S., Lehtipalo, K., Aalto, P., Vana, M., Mirme, A., Mirme, S., Hõrrak, U., Plass-Dülmer, C., Stange, G., Kiss, G., Hoffer, A., Törõ, N., Moerman, M., Henzing, B., de Leeuw, G., Brinkenberg, M., Kouvarakis, G. N., Bougiatioti, A., Mihalopoulos, N., O’Dowd, C., Ceburnis, D., Arneth, A., Svenningsson, B., Swietlicki, E., Tarozzi, L., Decesari, S., Facchini, M. C., Birmili, W., Sonntag, A., Wiedensohler, A., Boulon, J., Sellegri, K., Laj, P., Gysel, M., Bukowiecki, N., Weingartner, E., Wehrle, G., Laaksonen, A., Hamed, A., Joutsensaari, J., Petäjä, T., Kerminen, V.-M., and Kulmala, M.: EUCAARI ion spectrometer measurements at 12 European sites - analysis of new particle formation events, Atmos. Chem. Phys., 10, 7907-7927, doi:10.5194/acp-10-79072010, 2010.

McMurry, P. H.: Photochemical aerosol formation from $\mathrm{SO}_{2}-\mathrm{a}$ theoretical-analysis of smog chamber data, J. Colloid Interf. Sci., 78, 513-527, 1980.

McMurry, P. H.: New particle formation in the presence of an aerosol-rates, time scales, and sub-0.01 $\mu \mathrm{m}$ size distributions, J. Colloid Interf. Sci., 95, 72-80, 1983.

McMurry, P. H. and Friedlander, S. K.: New particle formation in the present of an aerosol, 13, 1635-1651, 1979.

McMurry, P. H., Woo, K. S., Weber, R., Chen, D. R., and Pui, D. Y. H.: Size distributions of 3-10 nm atmospheric particles: implications for nucleation mechanisms, Philos. T. Roy. Soc. A, 358, 2625-2642, 2000.

Merikanto, J., Spracklen, D. V., Mann, G. W., Pickering, S. J., and Carslaw, K. S.: Impact of nucleation on global CCN, Atmos. Chem. Phys., 9, 8601-8616, doi:10.5194/acp-9-8601-2009, 2009.

Metzger, A., Verheggen, B., Dommen, J., Duplissy, J., Prevot, A. S. H., Weingartner, E., Riipinen, I., Kulmala, M., Spracklen, D. V., Carslaw, K. S., and Baltensperger, U.: Evidence for the role of organics in aerosol particle formation under atmospheric conditions, P. Natl. Acad. Sci. USA, 107, 6646-6651, 2010.

Murphy, S. M., Sorooshian, A., Kroll, J. H., Ng, N. L., Chhabra, P., Tong, C., Surratt, J. D., Knipping, E., Flagan, R. C., and Se- infeld, J. H.: Secondary aerosol formation from atmospheric reactions of aliphatic amines, Atmos. Chem. Phys., 7, 2313-2337, doi:10.5194/acp-7-2313-2007, 2007.

Nadykto, A. B., Yu, F. Q., Jakovleva, M. V., Herb, J., and Xu, Y. S.: Amines in the Earth's Atmosphere: A Density Functional Theory Study of the Thermochemistry of Pre-Nucleation Clusters, Entropy, 13, 554-569, 2011.

Riipinen, I., Sihto, S.-L., Kulmala, M., Arnold, F., Dal Maso, M. Birmili, W., Saarnio, K., Teinilä, K., Kerminen, V.-M., Laaksonen, A., and Lehtinen, K. E. J.: Connections between atmospheric sulphuric acid and new particle formation during QUEST IIIIV campaigns in Heidelberg and Hyytiälä, Atmos. Chem. Phys., 7, 1899-1914, doi:10.5194/acp-7-1899-2007, 2007.

Schade, G. W. and Crutzen, P. J.: Emission of aliphatic-amines form animal husbandry and reactions-potential source of $\mathrm{N}_{2} \mathrm{O}$ and HCN, J. Atmos. Chem., 22, 319-346, 1995.

Seinfeld, J. H. and Pandis, S. N.: Atmospheric chemistry and physics: from air pollution to climate change, John Wiley and Sons, Inc, New York, 1998.

Sihto, S.-L., Kulmala, M., Kerminen, V.-M., Dal Maso, M., Petäjä, T., Riipinen, I., Korhonen, H., Arnold, F., Janson, R., Boy, M., Laaksonen, A., and Lehtinen, K. E. J.: Atmospheric sulphuric acid and aerosol formation: implications from atmospheric measurements for nucleation and early growth mechanisms, Atmos. Chem. Phys., 6, 4079-4091, doi:10.5194/acp-6-4079-2006, 2006.

Sipila, M., Berndt, T., Petaja, T., Brus, D., Vanhanen, J., Stratmann, F., Patokoski, J., Mauldin, R. L., Hyvarinen, A. P., Lihavainen, H., and Kulmala, M.: The Role of Sulfuric Acid in Atmospheric Nucleation, Science, 327, 1243-1246, 2010.

Smith, J. N., Barsanti, K. C., Friedli, H. R., Ehn, M., Kulmala, M., Collins, D. R., Scheckman, J. H., Williams, B. J., and McMurry, P. H.: Observations of aminium salts in atmospheric nanoparticles and possible climatic implications, P. Natl. Acad. Sci. USA, 107, 6634-6639, 2010.

Sorooshian, A., Murphy, S. M., Hersey, S., Gates, H., Padro, L. T., Nenes, A., Brechtel, F. J., Jonsson, H., Flagan, R. C., and Seinfeld, J. H.: Comprehensive airborne characterization of aerosol from a major bovine source, Atmos. Chem. Phys., 8, 5489-5520, doi:10.5194/acp-8-5489-2008, 2008.

Spracklen, D. V., Carslaw, K. S., Kulmala, M., Kerminen, V. M., Sihto, S. L., Riipinen, I., Merikanto, J., Mann, G. W., Chipperfield, M. P., Wiedensohler, A., Birmili, W., and Lihavainen, H.: Contribution of particle formation to global cloud condensation nuclei concentrations, Geophys. Res. Lett., 35, L06808, doi:10.1029/2007g1033038, 2008.

Turco, R. P., Zhao, J. X., and Yu, F. Q.: A new source of tropospheric aerosols: Ion-ion recombination, Geophys. Res. Lett., 25, 635-638, 1998.

Wang, L., Khalizov, A. F., Zheng, J., Xu, W., Ma, Y., Lal, V., and Zhang, R. Y.: Atmospheric nanoparticles formed from heterogeneous reactions of organics, Nat. Geosci., 3, 238-242, 2010a.

Wang, L., Lal, V., Khalizov, A. F., and Zhang, R. Y.: Heterogeneous Chemistry of Alkylamines with Sulfuric Acid: Implications for Atmospheric Formation of Alkylaminium Sulfates, Environ. Sci. Technol., 44, 2461-2465, 2010 b.

Weber, R. J., Marti, J. J., McMurry, P. H., Eisele, F. L., Tanner, D. J., and Jefferson, A.: Measured atmospheric new particle formation rates: Implications for nucleation mechanisms, Chem. Eng. 
Commun., 151, 53-64, 1996.

Weber, R. J., Marti, J. J., McMurry, P. H., Eisele, F. L., Tanner, D. J., and Jefferson, A.: Measurements of new particle formation and ultrafine particle growth rates at a clean continental site, J. Geophys. Res., 102, 4375-4385, 1997.

Weber, R. J., Chen, G., Davis, D. D., Mauldin, R. L., Tanner, D. J., Eisele, F. L., Clarke, A. D., Thornton, D. C., and Bandy, A. R.: Measurements of enhanced $\mathrm{H}_{2} \mathrm{SO}_{4}$ and 3-4 nm particles near a frontal cloud during the First Aerosol Characterization Experiment (ACE 1), J. Geophys. Res., 106, 24107-24117, 2001.

Woo, K. S., Chen, D. R., Pui, D. Y. H., and McMurry, P. H.: Measurement of Atlanta aerosol size distributions: Observations of ultrafine particle events, Aerosol Sci. Tech., 34, 75-87, 2001.

Young, L. H., Benson, D. R., Kameel, F. R., Pierce, J. R., Junninen, H., Kulmala, M., and Lee, S.-H.: Laboratory studies of $\mathrm{H}_{2} \mathrm{SO}_{4} / \mathrm{H}_{2} \mathrm{O}$ binary homogeneous nucleation from the $\mathrm{SO}_{2}+\mathrm{OH}$ reaction: evaluation of the experimental setup and preliminary results, Atmos. Chem. Phys., 8, 4997-5016, doi:10.5194/acp-8-4997-2008, 2008.

Yu, F. Q. and Turco, R. P.: Ultrafine aerosol formation via ionmediated nucleation, Geophys. Res. Lett., 27, 883-886, 2000.

Yu, F. Q. and Turco, R. P.: From molecular clusters to nanoparticles: Role of ambient ionization in tropospheric aerosol formation, J. Geophys. Res., 106, 4797-4814, 2001.
Yu, F., Wang, Z., Luo, G., and Turco, R.: Ion-mediated nucleation as an important global source of tropospheric aerosols, Atmos. Chem. Phys., 8, 2537-2554, doi:10.5194/acp-8-2537-2008, 2008.

Zhang, R. Y., Suh, I., Zhao, J., Zhang, D., Fortner, E. C., Tie, X. X., Molina, L. T., and Molina, M. J.: Atmospheric new particle formation enhanced by organic acids, Science, 304, 1487-1490, 2004.

Zhang, R. Y., Wang, L., Khalizov, A. F., Zhao, J., Zheng, J., McGraw, R. L., and Molina, L. T.: Formation of nanoparticles of blue haze enhanced by anthropogenic pollution, P. Natl. Acad. Sci. USA, 106, 17650-17654, 2009.

Zhao, J., Khalizov, A., Zhang, R. Y., and McGraw, R.: HydrogenBonding Interaction in Molecular Complexes and Clusters of Aerosol Nucleation Precursors, J. Phys. Chem. A, 113, 680-689, 2009.

Zhao, J., Eisele, F. L., Titcombe, M., Kuang, C. G., and McMurry, P. H.: Chemical ionization mass spectrometric measurements of atmospheric neutral clusters using the cluster-CIMS, J. Geophys. Res., 115, D08205, doi:10.1029/2009jd012606, 2010. 